\title{
Fish landings and Oman shelf area
}

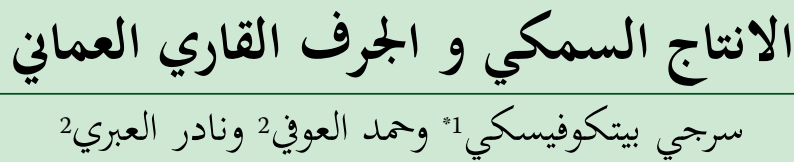

AbSTRACT. Data from five field surveys carried out along the shelf in the $20-250 \mathrm{~m}$ depth range and historical data on artisanal fishery were analyzed. A positive linear relationship between the demersal fish biomass and the shelf area was pronounced for a certain (intermediate) stratum only: 50-100m. No statistical link was found for the strata above it $(25-50 \mathrm{~m})$ and beneath it $(100-150 \mathrm{~m}$ and $150-250 \mathrm{~m})$. The pronounced one was associated with the low boundary of the oxygen minimum zone impinging on the shelf. Annual landings of demersal fishes in the region with the largest shelf area exceeded landings in the region with the smallest area by as much as 1.6 times. The ratio of small pelagic to demersal fish landings decreased as a factor of 10 , from small to large shelf areas.

KEYwordS: Fish landings; Arabian Sea; continental shelf; oxygen minimum zone; Oman

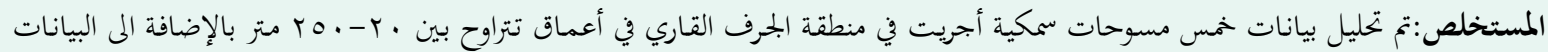

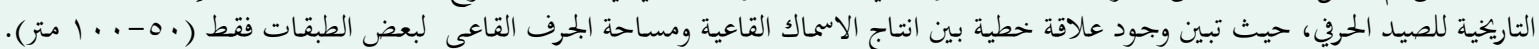

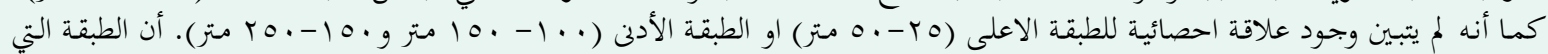

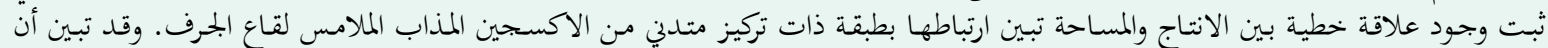

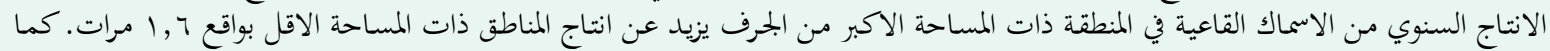

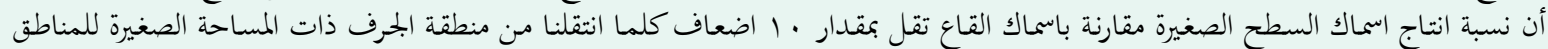

$$
\begin{aligned}
& \text { ذات المساحات الاعلى. } \\
& \text { الكلمات المفتاحية: الانتاج السمكي، بحر العرب، الجرف القاري، طبقة ذات أكسجين متدني }
\end{aligned}
$$

\section{Introduction}

$\mathrm{L}$ ong-term estimates of fisheries production over various ecosystems of the World Ocean have indicated a large proportion of this production to be associated with shelf waters (Caddy, 1993; Caddy et al., 1998).

On a regional scale, the Arabian Sea is the basin notorious for a variety of continental shelf geomorphology. The eastern part has a huge shallow shelf area underlying the coast of India. The marine fish production of this country has increased six times in the last 50 years and reached $\sim 3.2$ million tons in 2008, providing employment to about one million fishermen (Rao, 2010).

The western part of the Arabian Sea faces a much less extended shelf along the Omani coast. Oman fishery incorporates commercial and artisanal constituents with the latter accounting for $96 \%$ of landings. In 2008 , the fishery landed $\sim 102,000$ metric tons and employed 38,000 fishermen operating 14,796 fishing boats, $90 \%$ of which are fiberglass boats 8-10 meters in length (Fisher-

\footnotetext{
*1 Sergey Piontkovski ( Sultan Qaboos University, College of Agricultural and Marine Sciences, Dpt. of Marine Science and Fisheries. Box 34, Al-Khod 123. Sultanate of Oman. email: spion@squ.edu.om.

2 Ministry of Agriculture and Fisheries Wealth. PO 467, Muscat 113. Sultanate of Oman.
}

ies Statistics Book, 2008).

Artisanal landings exhibit seasonal variation associated with monsoonal winds as well as the variety of fishing efforts. Shelf areas change notoriously from $\sim 2,000$ $\mathrm{km}^{2}$ in the northernmost part of the Arabian Sea to $\sim 17,000 \mathrm{~km}^{2}$ in its southern part. The role of the shelf area as the factor affecting fish landings is poorly understood in regional fishery.

In the Arabian Sea demersal fishes accounted for 33\% of the total landings along the Omani shelf during the latest decade (2002-2012). However, while important, the demersal fishes are still poorly investigated in terms of spatial-temporal distribution of standing stock exhibiting gradual variance (McIlwain et al., 2011).

We aimed to seek the relationship between the shelf area and the biomass of demersal fishes, which might be useful in management of shelf resources because this management is gradually affected by available set of regionally sensitive indicators linking shelf geomorphology, fishery, and the fish community structure (Trenkel and Rochet, 2003). Also, the evaluation of relationship is regionally important because the shelf area affects the carrying capacity, which is a measure of the biomass of populations that can be supported by the ecosystem (Mantua and Hare, 2002). 


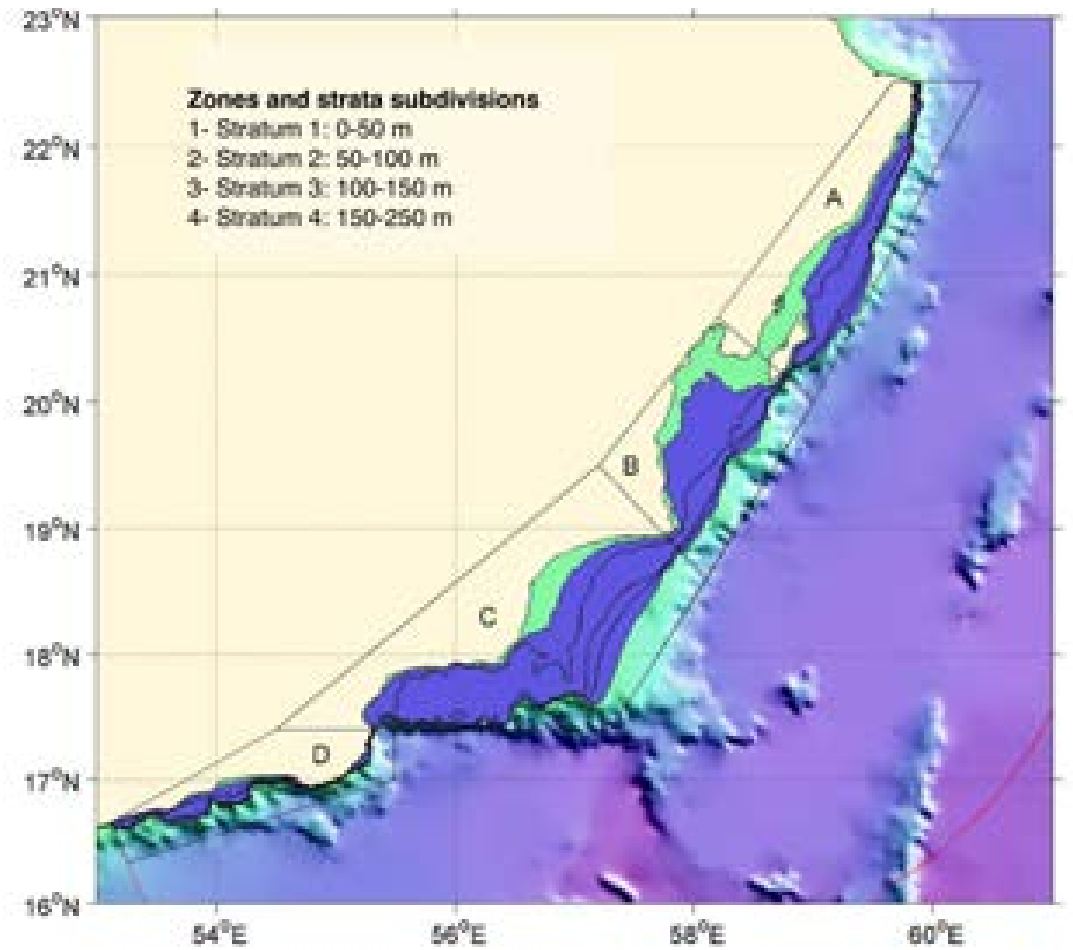

Figure 1. Scheme of shelf stratified sampling during the "Mustaqila1" surveys (McKoy et al, 2009). A-D: shelf zones corresponding to (A) Al-Sharkiyah region, (B) Al-Wusta region), and (C+D) Dhofar region.

\section{Materials and methods}

Seasonal surveys (these consisted of five voyages of $\mathrm{R} / \mathrm{V}$ "Mustagila1") were carried out along the shelf in the 20$250 \mathrm{~m}$ depth range from the Ras al Hadd region to the southernmost part of the Omani shelf (to the Yemen boarder). These surveys encompassed 4 shelf zones (A, B, C, and D) with 4 depth strata in each zone (Fig. 1).

The Independent 1 "mother" trawl was used for all demersal fish surveys. All "Mustaquila1" trawl surveys were standardized in a way that duration, speed, strata and gear were the same during all voyages standardizing in effect sampling effort. This allowed the total biomass to be compared over regions, depth strata and periods.

A towing speed of 3.5 knots, a standard towing distance of 2.0 nautical miles, and trawl rigging to achieve sweeping gear angles of less than $20^{\circ}$ were used. Tows were carried out during daylight. The catch was weight- ed on motion compensated scales and identified to species.

Data on the total biomass for each survey (in metric tons) were retrieved from cruise reports (McKoy et al., 2009) averaged by strata and zones, for all demersal fish and shark species, combined and based on their size range. Biomasses from the trawl survey was calculated using wingspread as the area swept.

Fish surveys were accompanied by Conductivity Temperature Depth profiles (CTD). Conductivity, temperature, density, depth, and dissolved oxygen concentration were measured using an RBR CTD probe deployed from the vessel (Table 1).

A Simrad EK60 acoustic backscatter with $38 \mathrm{kHz}$, $120 \mathrm{kHz}$ and $200 \mathrm{kHz}$ transducers was used for routine acoustic surveys. The nearshore transects across the shelf began at a $200 \mathrm{~m}$ depth and extended up to $8 \mathrm{~km}$ offshore. When deep-scattering layers were identified

Table 1. General characteristics of the "Mustaqila1" voyages.

$\begin{array}{lllcc}\text { Voyage code } & \text { Time range } & \begin{array}{l}\text { No. of demersal } \\ \text { stations }\end{array} & \begin{array}{l}\text { No. of CTD } \\ \text { stations }\end{array} & \begin{array}{l}\text { No. of pelagic } \\ \text { of video } \\ \text { camera stations }\end{array} \\ \text { OMA0701 } & \text { Sep-Oct 2007 } & 101 & 386 & 18 \\ \text { tion tows }\end{array}$



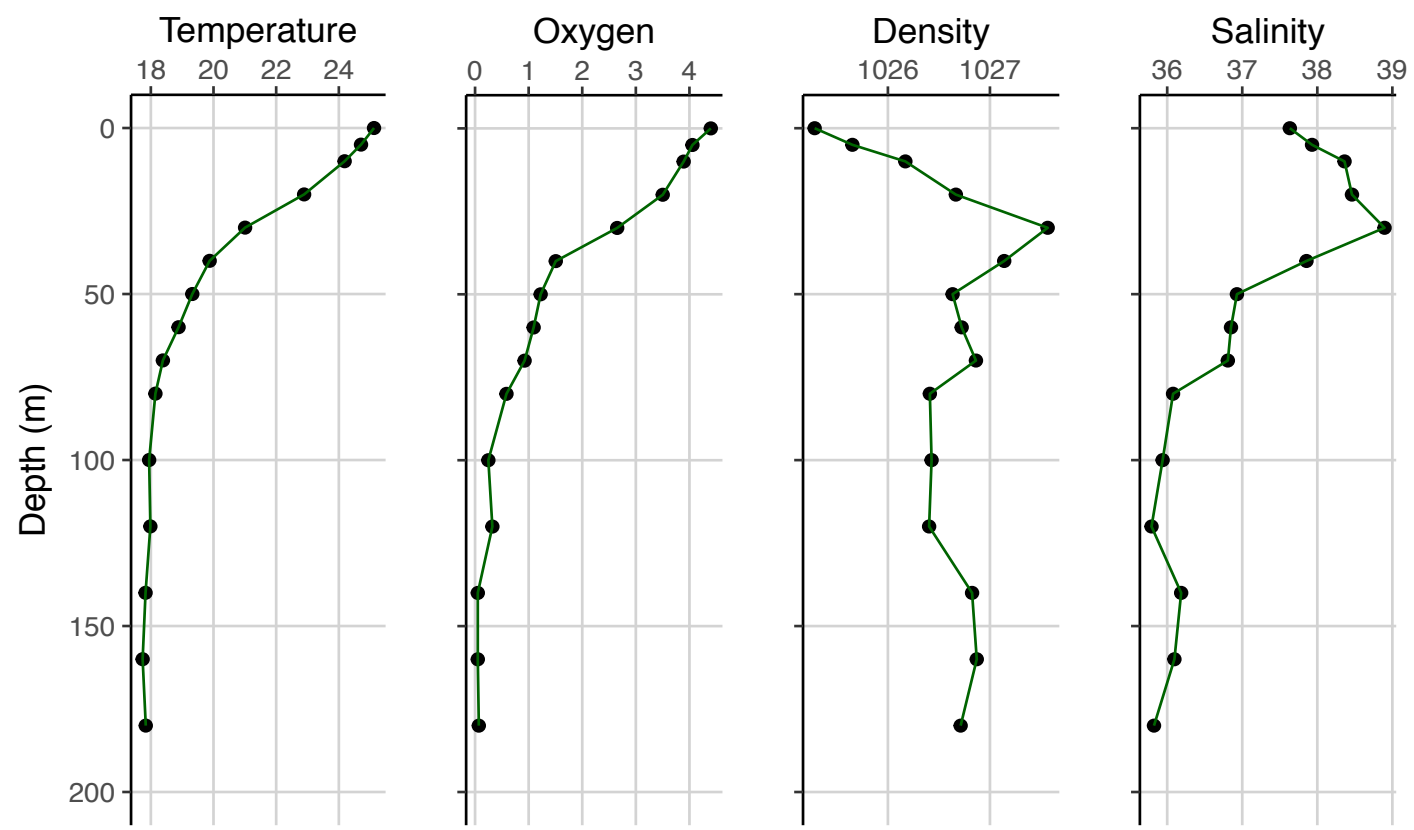

Figure 2. Vertical profiles of temperature, salinity, density, and dissolved oxygen concentration (September 2007, Zone A).

on the sounder, pelagic trawls were used to catch the organisms. Later on, catches were sorted by species. The P55 midwater trawl with a $10 \mathrm{~mm}$ liner in the cod end was used to sample mesopelagic organisms.

Along with data on the "Mustaqila 1" surveys, we used historical data on fish landings which are routinely monitored by the Department of Fisheries Statistics based on a sampling system established by the Oman-American USAID project (Mathews et al., 2001). Monthly traditional (artisanal) landings were retrieved from the annual reports published by the Ministry of Agriculture and Fisheries Wealth (Fishery Statistics Book, 2008).

\section{Results}

The "Mustaqila 1" field surveys began in September 2007 and captured a weakening South-west Monsoon. During this monsoon, the Omani shelf was occupied by the East Arabian Current (Oman Coastal Current) directed north-westward and fed by limbs of the Somali Current (Böhm et al., 1998). The CTD casts carried out along the shelf all implied fairly stable intra-seasonal structure in vertical distribution of temperature, salinity, density, and the dissolved oxygen concentration (Figure 2).

These major parameters resembled the thermocline, the picnocline and the oxycline all pronounced in the range from 30 to $100 \mathrm{~m}$. For example, the temperature decreased from $21^{\circ} \mathrm{C}$ to $18^{\circ} \mathrm{C}$ in this layer; the oxygen concentration dropped from 2.7 to $0.2 \mathrm{ml} \mathrm{L}^{-1}$. The seasonal mode of monsoonal winds changes these patterns; however, the seasonality was analyzed elsewhere (Piontkovski and Al-Oufi, 2014). Given plots exemplified the location and strength of vertical gradients, which are important in the context of subsequent discussion.

As far as the vertical distribution of demersal fish biomass is concerned, data from all surveys covering all strata and seasons allowed us to elucidate an exponential decrease of mean biomass over depth, from 20 to $250 \mathrm{~m}$ (Figure 3).

The deviations from this trend are the ones in which the biomass in the intermediated stratum $(50-100 \mathrm{~m})$ exceed that in the stratum above $(20-50 \mathrm{~m})$ and strata below (100-150 $\mathrm{m}$ and 150-250 m). All these deviations were noticed for zones $\mathrm{A}, \mathrm{C}$, and $\mathrm{D}$, and all dealt with the fall season, in which the dissolved oxygen concentration was minimal in comparison to other seasons. The 50-100m stratum was located in the low part of the oxycline. The biomass of demersal fishes in this stratum (for the "deviates") exceeded the upper stratum biomass by a factor of two and the low stratum biomass by a factor of 30 .

Data on the above displayed vertical distribution of temperature, salinity, dissolved oxygen concentration, and biomass over strata were subjected to the Principal Component Analysis (PCA) to understand the role of measured environmental factors in terms of their contribution to the total variance of the biomass. The PCA is a data compression procedure which enables to reduce the number of variables to a few Principal Components (Factors) reflecting the compression result. A statistical technique of PCA is based on a rotation of the coordinate system of the variables in a way that in the new coordinate system of these variables is maximally uncorrelated.

We used the Varimax -normalized matrix of vari- 


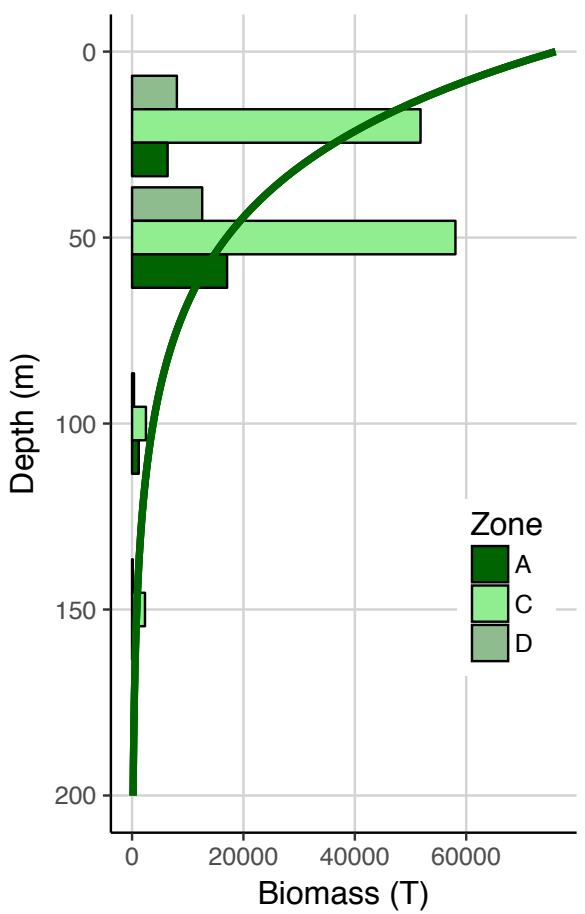

Figure 3. Vertical distribution of demersal fish biomass. Depth values on the vertical axis stand for the upper boundary of the trawl strata (20-50, 50-100, 100-150, and $150-250 \mathrm{~m}$ ). Mean B is averaged biomass (over all zones and voyages). A, C, and D are shelf zones (from Figure 1). Horizontal axis stands for a wingspread biomass for all fish and shark species over the total survey area. Mean $\mathrm{B}(\mathrm{x})=$ $76025.5 \exp (-0.03$ depth); $r=-0.89, p=0.1$ (linear fit).

ables. The Varimax procedure amounts to a variance maximizing rotation of the original variable space. The transformed product was further treated as the measure of similarity between variables. The extraction of eigenvectors of the matrix enables one to reduce the diversity in the system of numerous variables to a few Principal Components (Factors) in which the component scores are standardized units based on a correlation matrix. In other words, the eigenvectors are the results of the projection of the original variable axes into the space of new Principal Components. Eigenvectors forming the principal components are based on the similarity coefficients in linear combinations of variables. Once the internal structure of Principal Components is elucidated and these components are interpreted in some way, the relationship between the first two components (most important by loading) might be analyzed in the form of a scatterplot. In the space of two components, distances between sites approximate the Euclidean distance of the transformed data.

In our case, the similarity of distribution of variables over the space of the first two factors (Principal Components) showed an obvious split of data into three clusters

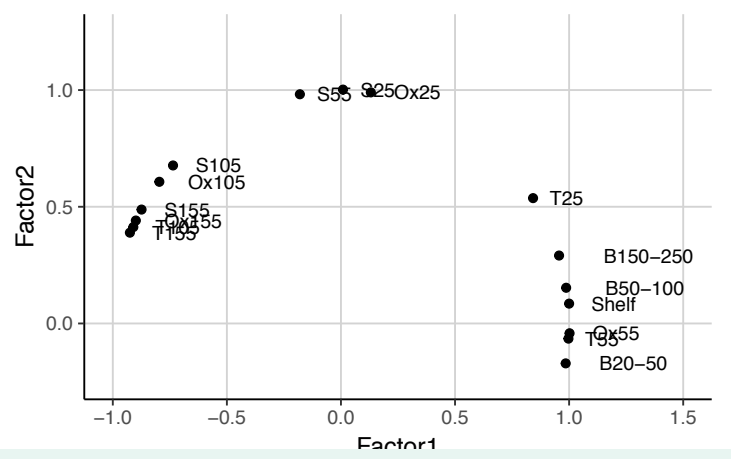

Figure 4. Mean wet weight $(\mathrm{kg} / \mathrm{m} 2)$ of macro-fouling communities developed on ceramic tiles exposed to fouling in Marina Bandar Al Rawdah.

(Fig. 4).

The first Principal Component explained 69\% of the system total variance, whereas the other $31 \%$ were attributed to the second component. In terms of internal structure, the first and the second Principal Components are different by variables driving the factor load. For instance, first Principal Component (Factor 1) is a complex of physical-biological variables in which variations of the biomass coupled with temperature and oxygen in the thermocline and oxycline have the highest scores by contributing to this factor. In terms of coupling in the space of two Principal Components, the biomass in the layer 50-100 $\mathrm{m}$ and the size of shelf areas are standing most close to each other (Fig. 4). As for Factor 2 contributing the remaining of the system total variance, it is loaded exclusively by physical variables (which are temperature, salinity, and oxygen coupling in layers beneath the thermocline).

Further on, to analyze statistical coupling between the parameters contributed to the first Principal Component, the Ridge Multiple Regression was employed. The essence of Ridge Regression is the estimation of regression coefficients in the form of

$$
\hat{\beta}=\left(X^{T} X+k I\right)^{-1} X^{T} y
$$

where $k$ is the ridge parameter, $\mathbf{I}$ is the identity matrix, and $\mathbf{X}$ is the design matrix. When $\mathbf{X}$ has a linear dependence, the matrix $\mathbf{X}^{\mathrm{T}} \mathbf{X}$ is close to singular. Small positive values of $k$ reduce the variance of the estimates. In turn, the reduced variance of ridge estimates gives a smaller mean square error when compared to least-squares estimates. Ridge Regression is tightly associated with the outcomes of the Principal Component Analysis. It allows the large variance Principal Components to have a larger influence on the final model compared to the low variance Principal Components. In our case, the result of the Ridge Multiple Regression might be characterized by the summary for the dependent variable (which is the biomass) implying that the size of shelf is the variable explaining a dominant part of the biomass variations over 
Table 2. Parameters of regression equations representing the total biomass of demersal fish $(\mathrm{Y})$ as a positive linear function of the shelf size (X).

\begin{tabular}{lllll|} 
Voyage & Time range & Equation & R2 & p-level \\
OMA0701 & Sep-Oct 2007 & $\mathrm{Y}=-18367.54+4.32 \mathrm{X}$ & 0.98 & 0.05 \\
OMA0702 & Nov-Dec 2007 & $\mathrm{Y}=-5580.91+3.33 \mathrm{X}$ & 0.82 & 0.05 \\
OMA0801 & Jan-Mar 2008 & $\mathrm{Y}=2169.85+2.41 \mathrm{X}$ & 0.91 & 0.05 \\
OMA0802 & Apr-Jun 2008 & $\mathrm{Y}=6136.36+2.85 \mathrm{X}$ & 0.76 & 0.05 \\
OMA0803 & Aug-Sep 2008 & $\mathrm{Y}=1273.59+1.11 \mathrm{X}$ & 0.49 & 0.05
\end{tabular}

the Omani shelf. The parameters of the Ridge Multiple Regression were as follows: $R^{2}=0.98$, Standard error= $0.12, \mathrm{p}<0.07$.

The variation of the size area and other geomorphological characteristics of the Omani shelf is quite diverse (Figure 1). One could observe a wide area between $17 \mathrm{oN}$ to $19 \mathrm{oN}$, a midsize fragment between $21^{\circ} \mathrm{N}$ to $22^{\circ} \mathrm{N}$, a narrow strip zone in the southernmost part $(17 \mathrm{oN}$ $17.5^{\circ} \mathrm{N}$ ), a "bath-type" fragment in the westernmost part of the shelf in the Sea of Oman (not shown in the figure), among other types of fragments. This diversity sounds potentially important for carrying capacity characterizing the biomass of organisms the shelf could accommodate.

The analysis of the variance of the total biomass of demersal fishes implied that the variance over different shelf regions (zones A to D) during one season exceeded the variance within a zone over seasons (sampled by 5 consecutive voyages). Correspondently, we computed regressions linking the biomass with the shelf size for all voyages carried out during different seasons (Table 2 ).

High values of the determination coefficient $\left(R^{2}\right)$ pointed out the usefulness to assemble all five voyages in one plot. The generalized regression synthesizing the whole shelf and representing the total biomass of demersal fish as a positive linear function of the shelf area is displayed in Figure 5.

The coefficient of determination $\left(\mathrm{R}^{2}\right)$ has pointed out that the statistical link in figure 5 explained $66 \%$ of observed biomass variation. As far as shelf characteristics are concerned, the shelf areas overlooking the western Arabian Sea exhibited almost 9 fold range extending from $\sim 2000 \mathrm{~km}^{2}$ to $\sim 17000 \mathrm{~km}^{2}$.

Interestingly, the relationship between the demersal fish biomass and the shelf area was pronounced for a certain (intermediate) stratum only: $50-100 \mathrm{~m}$. No statistical link was found for the strata above it (25-50 m) and beneath it (100-150 $\mathrm{m}$ and $150-250 \mathrm{~m})$. The pronounced one was associated with the low part of the oxygen minimum zone impinging on the shelf.

Species diversity of demersal fishes was quite high. The taxonomic analysis of trawls carried out onboard enabled the abundant families and groups to be summarized, in terms of their contribution to the total trawlable biomass (Table 3; McKoy et al., 2009). The percentage of 28 categories given in the table was low in general

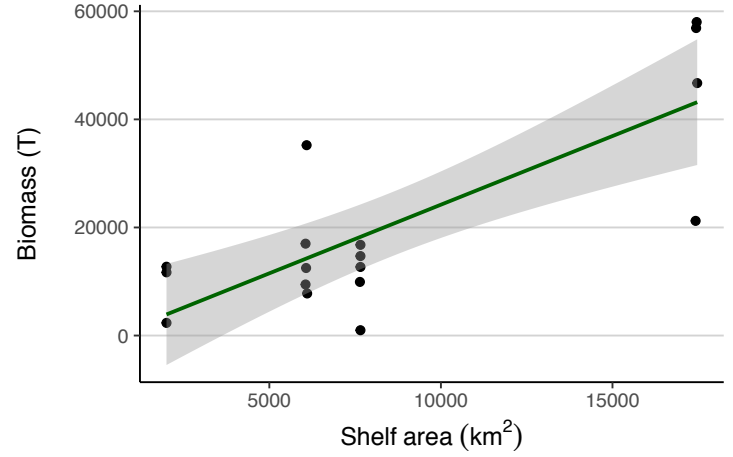

Figure 5. Relationship between demersal fish biomass and shelf area (50-100 $\mathrm{m}$; all voyages). $\mathrm{Y}=-1032.3+2.7 \mathrm{X}$; $\mathrm{R} 2=0.66$. Grayed area: 95\% confidence level.

(constituting 7\% for groups and 6\% for families), with no spatial pattern pronounced over shelf zones.

Data on trawl catches from the "Mustaqila1" voyages were compared to data on artisanal landings of demersal fishes along the Omani shelf, for the year 2008. Historical data available from the statistical reports of the Ministry of Agriculture and Fisheries Wealth resemble three major regions of fishery in the western Arabian Sea, namely Al-Sharkiyah, Al-Wusta, and Dhofar. Annual landings of demersal fish in Dhofar (with the largest shelf) area exceeded landings in Al-Sharkiyah by as much as 1.6 times (with the smallest shelf area). In terms of sustainability it might be noticed that the averaged long-term ratio for these two regions is 1.7 (2008-2012).

We emphasized the fact that the biomass-to-shelf area relationship is coupled with the location of the seasonal oxycline (Fig. 2) associated with the $30-100 \mathrm{~m}$ depth range. The oxycline location exhibits seasonal as well as interannual fluctuations, discussed elsewhere (Piontkovski and Al-Oufi, 2014).

In order to understand whether the shelf area could affect the carrying capacity of pelagic fishes we analyzed two groups of data. The first one was represented by acoustic assessments of sardine biomass over regions during the "Mustaquila1" voyages. The second one was data on artisanal landings of total pelagic fish and sardines (analyzed separately) retrieved from archives (Fisheries Statistics Book, 2012). Sardines were selected for both cases because they contribute about 30-50\% 
Table 3. Contribution of groups and families (\%) into the total biomass of mesopelagic fishes over regions per zone.

\begin{tabular}{|c|c|c|c|c|}
\hline Family or group & A & B & $\mathrm{C}$ & D \\
\hline Rays and skates & 17.8 & & & \\
\hline Batoidea & 19.9 & 22.9 & 13.1 & 11.8 \\
\hline Catfhish & & 10 & & 2.1 \\
\hline Siluriformes & 6.5 & 12.9 & 0.2 & 0.5 \\
\hline Lizardfishes & & & 16 & \\
\hline Synodovtidae & 14 & 1.9 & 4 & 0.3 \\
\hline Sea basses & & 1.5 & 1.7 & 5.8 \\
\hline Serranidae & 0.6 & 0.2 & 0.9 & 0.7 \\
\hline Jacks & & & 1.5 & 2.6 \\
\hline Pompanos & 2.3 & 4.7 & 7.7 & 3.4 \\
\hline Carangidae & 5.4 & 3.9 & & \\
\hline Snappers & & & 2.3 & 4.8 \\
\hline Lutjanidae & 0.4 & 0.1 & 0.3 & 0.4 \\
\hline Grunts & 5.6 & 3.7 & & 5.8 \\
\hline Haemulidae & 10.9 & 15.3 & 4.1 & 7.7 \\
\hline Threadfin breams & 24.3 & 17 & 4.7 & \\
\hline Nemipteridae & 20.4 & 13.2 & 16.8 & 1.7 \\
\hline Emperors & 3 & 12.3 & 8.2 & 11 \\
\hline Lethrinidae & 1.2 & 1.9 & 4 & 21.2 \\
\hline Porgies & 7.7 & 4.3 & 19.4 & 23 \\
\hline Sparidae & 10.8 & 9.3 & 17.6 & 16.9 \\
\hline Drums & 1.2 & 1.7 & 6 & 5.5 \\
\hline Sciaenidae & 0.4 & 1.4 & 0.4 & 17.4 \\
\hline Barracuds & & & 6.2 & 10 \\
\hline Sphyraenidae & 1.2 & 1.6 & 0.3 & 1 \\
\hline Cutlassfishes & 5.3 & 2.3 & & \\
\hline Trichiuridae & 1.1 & 2.6 & 0.4 & 0.1 \\
\hline Pufferfishes & & & 14.2 & 2.3 \\
\hline Tetraodontidae & 0.2 & 0.1 & 0.3 & 0.4 \\
\hline
\end{tabular}

to Omani artisanal landings over regions. In analyzing landings, we had to partially alter the shelf regions, in order to take into account (to eliminate as the factor) the number of boats involved. Therefore, the regions selected for this analysis were the Muscat shelf (with 1710 boats active in 2008), the Al-Wusta region (with 1801 boat), and Dhofar (with 2075 boats). No statistical relationships were found between the shelf area and landings, as well as the shelf area and acoustically measured sardine biomass. This indicates that the standing stock of dominant pelagic species and their landings were not constrained by the shelf area.

One of the integrative characteristics featuring the structure of fish communities is the ratio of small pelagic to demersal biomass reported from fish landings (Caddy et al., 1998). We calculated this ratio using histori-

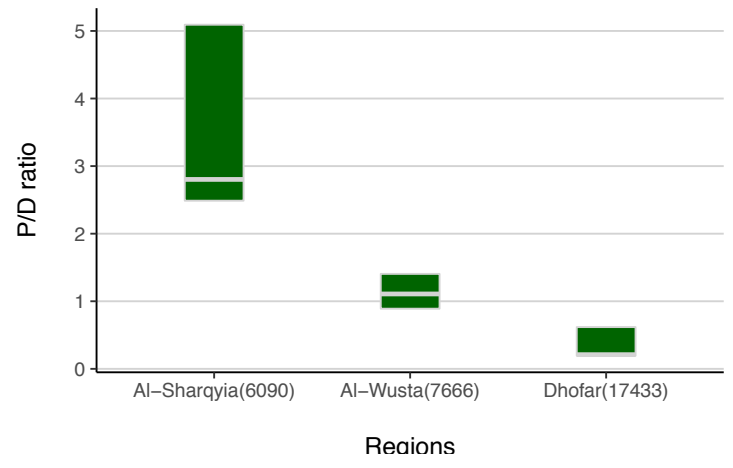

Figure 6. Relationship between the $\mathrm{P} / \mathrm{D}$ ratio and shelf area (2010-2012). Numbers in parentheses: shelf area of regions $\left(\mathrm{km}^{2}\right)$. Shaded rectangles stand for $25-75 \%$ quartiles of distribution.

cal data on pelagic and demersal fish landings available for the three shelf regions of the western Arabian Sea, namely Al-Sharkiya (with the shelf area of $6,090 \mathrm{~km}^{2}$ ), Al-Wusta $\left(7,666 \mathrm{~km}^{2}\right)$, and Dhofar $\left(17,433 \mathrm{~km}^{2}\right)$. In general, these regions correspond to zones $\mathrm{A}, \mathrm{B}$, and $\mathrm{C}+\mathrm{D}$, in Figure 1. The ratio of small pelagic to demersal group landings (the P/D ratio) was plotted as the function of shelf area (Fig. 6).

We selected data for the years when the number of boats was not much different over regions (i.e. about $20 \%)$. This enabled us to exclude the factor of fishing efforts. The $\mathrm{P} / \mathrm{D}$ ratio has decreased by a factor of 10 , from small to large shelf areas. The key variable regulating the decline of this ratio was pelagic landings which exhibited the 6 fold decrease complemented by the 3 fold increase in demersal landings, from small to large areas.

\section{Discussion}

The global scale comparisons pointed out that narrow oceanic shelves tend to have less demersal species than wide shelves and shelf seas (Bergstad, 2009). In our case, data on the percentage of 28 taxonomic categories ( Table 3) enable us to assume that variations of shelf area (in a given range) do not affect the diversity on the level of groups and families which occur in relatively uniform proportions through all shelf areas regardless of their size. As the factor affecting demersal community, the shelf size seems to be coupled with the concentration of dissolved oxygen.

In terms of vertical distribution of dissolved oxygen, the range of depth from 30 to $100 \mathrm{~m}$ was the most subjected to oxygen deficiency because of the location of oxycline. Therefore, the statistically significant relationship between demersal fish biomass and the shelf area was observed for this particular layer. A positive linear regression linking the total biomass with shelf area was quite stable, because it was observed throughout the seasonal cycle (i.e. all five voyages of R/V “Mustaqila 1"). 
Seasonal cycle of oxygen deficiency forces demersal fish to migrate closer to the coast, which can lead to a compression of the habitat and subsequent increase of landings in shallow waters. Indeed, data on some abundant groups are consistent with this hypothesis. For instance, the Emperor (Lethrinus nebulosus (Forsskål, 1775); one of abundant species) was in highest landings in November-December, which is the time of maximal oxygen depletion along the shelf (Piontkovski and Al-Oufi, 2014).

Carrying capacity of the Omani shelf builds up differently, for pelagic and demersal fish communities. The standing stock of the pelagic community is not constrained by the shelf area, whereas the demersal fish stock does. Along with that, both communities are affected by vertical distribution of the dissolved oxygen concentration (McIlwain et al., 2011; Piontkovski and Al-Oufi, 2014).

De Leiva Moreno et al. (2000) compared the pelagic to demersal landings ratio (the P/D ratio) over 14 shelf areas from enclosed European seas. They noticed that the ratio is affected not only by the shelf area but by the productivity (in the form of chlorophyll-a concentration), and characteristics of geographical enclosure associated in turn with catchments of basins.

The statistical linkages elucidated between the P/D ratio and the chlorophyll-a concentration, as well as between the ratio of catchment basin and chlorophyll allowed authors to suggest that the $P / D$ ratio may be a useful indirect index of availability of nutrients over European shelves. Also, they noticed that high P/D ratios are usually accompanied by high concentrations of surface chlorophyll-a. According to their summary, the oligotrophic shelf regions (of Levant, Aegean, Ionian, and Sardinia) can be characterized by mean P/D ratio 0.7; mesotrophic shelves (Balearic, Gulf of Lions, Adriatic, North Sea, and Irish Sea) have P/D 2.23; eutrophic shelves (of the Sea of Azov, Sea of Marmara, Black Sea, and Baltic Sea) are featured by P/D ratios standing higher.

Interestingly, the Omani shelf $\mathrm{P} / \mathrm{D}$ ratio covered all three categories-from oligotrophic through to eutrophic shelves (Fig. 6); this implied high variability of key structural indices of the ecosystem mediated by shelf geomorphology in association with environmental parameters. With this regard, the relationship we elucidated between the demersal fish biomass and the shelf area might play a useful role in understanding mechanisms mediating standing stocks of demersal fishes (as well as their landings) over shelves with different geomorphology. In terms of impacts, shelf geomorphology is coupled with the other parameters, such as the concentration of dissolved oxygen. In the western Arabian Sea, large supply of oxygenated waters originated from the south and advected horizontally by western boundary current (Resplandy et al., 2012). However, the ventilation rate of the oxycline associated with advection over large-sized versus small shelf areas could be different. Therefore the correlation between the P/D ratio and oxygen concentration at $100 \mathrm{~m}$ over four shelf areas distinct by its size, was high $(\mathrm{r}=0.9, \mathrm{p}=0.01)$.

\section{Acknowledgements}

This work is a contribution to the Cooperation Program between Sultan Qaboos University and the Ministry of Agriculture and Fisheries Wealth. Studies were supported by the Research Council grant \# ORG/EBR/11/002

\section{References}

Bergstad, O.A. 2009. Fish: Demersal Fish (Life histories, behavvior, adaptations). In: Marine Ecological Processes: A derivative of the Encyclopedia of Ocean Sciences. J.H.Steele, S.A.Thorpe, and K.K.Turekian (Eds.). London: Elsevier.

Böhm, E., Morrison, J.M., Manghnani, V., Kim, H-S., and Flagg, C.N. 1999. The Ras al Hadd jet: remotely sensed and acoustic doppler current profiler observations in 1994-1995. Deep-Sea Research II, 46: 15311549.

Caddy, J. F. 1993. Toward a comparative evaluation of human impacts on fishery ecosystems of enclosed and semienclosed seas. Reviews in Fisheries Science 1: 57-95.

Caddy, J. F., Carocci, F., and Coppola S. 1998. Have Peak Fishery Production Levels been Passed in Continental Shelf Areas? Some Perspectives Arising from Historical Trends in Production per Shelf Area. Journal of Northwest Atlantic Fishery Science 23: 191-219.

De Leiva Moreno, J.I., Agostini, V.N., Caddy, J.F., and Carocci, F. 2000. Is the pelagic-demersal ratio from fishery landings a useful proxy for nutrient availability? A preliminary data exploration for the semi-enclosed seas around Europe. ICES Journal of Marine Science 57: 1091-1102.

Fishery Statistics Book. 2008. Ministry of Fisheries Wealth: Sultanate of Oman. Muscat.

Fishery Statistics Book. 2011. Ministry of Fisheries Wealth: Sultanate of Oman. Muscat.

Mantua, N.J. and Hare, S.R. 2002. Large-scale climate variability and the carrying capacity of Alaska's Oceans and Watersheds. In: The status of Alaska's Oceans and Watersheds, pp.62-84. Accessed 16.01.2014. http://www.iser.uaa.alaska.edu/people/ colt/personal/final_report_part2.pdf\#page $=4$

Mathews, C.P., Al-Mamry, J., and Al-Habsy, S. 2001. Precautionary management of Oman's demersal fishery. In: First International Conference on Fisheries, Aquaculture and Environment in the NW Indian Ocean. Sultan Qaboos University: Muscat.

McIlwain, J.L., Harvey, E.S., Grove, S., Shiell, G., Al 
Oufi, H., and Al Jardani, N. 2011. Seasonal changes in a deep-water fish assemblage in response to monsoon-generated upwelling events. Fisheries Oceanography 20: 497-516.

McKoy, J., Bagley, N., Gauthier, S., and Devine, J. 2009. Fish Resources of the Arabian Sea coast of Oman: Project summary. In Technical Report 1. Bruce Shallard and Associates: Muscat.

Piontkovski, S.A., and Al-Oufi, H.S. 2014. The oxygen minimum zone and fish landings along the Omani shelf. Journal of Fisheries and Aquatic Science 9: 294310.

Rao, G S. 2010. Current Status and Prospects of Fishery Resources of the Indian Continental Shelf. In: Coastal Fishery Resources of India - Conservation and sustainable utilization. Meenakumari, B., Boopendranath, M.R., Edwin, L., Sankar, T., Gopal, N. \& Ninan, G. (Eds.) Society of Fisheries Technologists: Delhi, pp.1-13.

Resplandy, L., Levy, M., Bopp, L., Echevin, V., Pous, S., Sarma, V.V.S.S., and Kumar, D. 2012. Controlling factors of the oxygen balance in the Arabian Sea's OMZ. Biogeosciences 9: 5095-5109.
Trenkel, V.M., and Rochet, M-J. 2003. Performance of indicators derived from abundance estimates for detecting the impact of fishing on a fish community. Canadian Journal of Fisheries and Aquatic Sciences 60: $67-85$ 